\title{
Rapid Identification of Cunninghamella bertholletiae's Toxins/Secondary Metabolites via a Fermentation Technique
}

\author{
Elie Fereche Itoba-Tombo, Seteno Karabo Obed Ntwampe, John Baptist Nzukizi Mudumbi, Lukhanyo \\ Mekuto, Enoch Akinbiyi Akinpelu and Ogheneochuko U. Oputu
}

\begin{abstract}
Toxins/secondary metabolites produced by a cyanide tolerant/resistant fungal strain, i.e. Cunninghamella bertholletiae, were produced through a fermentation technique. Fungal mycelia $(0.05-0.4 \mathrm{~g})$ was inoculated and fermented in a $25 \mathrm{~mL}$ nutrient broth medium for $168 \mathrm{hrs}$ at $37^{\circ} \mathrm{C}$ in $40 \mathrm{~mL}$ Erlenmeyer flasks in a shaking incubator set at $70 \mathrm{rpm}$. A volume $(5 \mathrm{~mL})$ of the fermented extracts were filtered through a membrane, centrifuged, mixed with chloroform and dried-up through nitrogen blow-down prior reconstitution using $100 \%$ analytical grade methanol. Samples were analyzed for secondary metabolites identification using Liquid Chromatography-Mass Spectroscopy (LC/MS-TOF 6230). The results revealed the production of secondary metabolites; Silibinin and 11-Ketotestosterone from a cyanide resistant and/or tolerant $C$. bertholletiae.
\end{abstract}

Keywords - Cassava, Cunninghamella berthollethiae, Liquid Chromatography-Mass Spectroscopy, Secondary metabolites.

\section{INTRODUCTION}

A shelve life of cassava during a postharvest period is often threatened by spoilage from fungal and bacterial attacks [1]-[3]. Fungal species such as Cunninghamella sp., Penicillium sp., Aspergillus sp. and Fusarium sp. produce and release secondary metabolites which negatively affect the quality of the produce [2], [4], [5].

Most of the produced secondary metabolites, negatively affect agricultural products, thus leading to losses [6]-[8]. Toxins are biosynthetic compounds (metabolites) produced by toxicogenic fungal species and other microorganisms under natural or a controlled environment during their exposure to

E. F. Itoba-Tombo is with the Department of Environmental and Occupational Studies and is a member of Bioresource Engineering Research Group (BioERG), Department of Biotechnology, Cape Peninsula University of Technology, PO Box 652, Cape Town 8000, South Africa,.

Seteno Karabo Obed Ntwampe is with Engineering Research Group (BioERG), Department of Biotechnology, Cape Peninsula University of Technology, PO Box 652, Cape Town 8000, South Africa,

John Baptist Nzukizi Mudumbi. Seteno Karabo Obed Ntwampe is with Engineering Research Group (BioERG), Department of Biotechnology, Cape Peninsula University of Technology, PO Box 652, Cape Town 8000, South Africa.

Lukhanyo Mekuto is now with the University of Johannesburg, Department of Chemical Engineering, 2024, South Africa.

Enoch Akinbiyi Akinpelu was with Engineering Research Group (BioERG), Department of Biotechnology, he is now at the University of the North West, South Africa

Ogheneochuko U. Oputu is with the Department of Chemistry, Peninsula University of Technology, PO Box 652, Cape Town 8000, South Africa. harsh environmental conditions [9]. These compounds, also known as secondary metabolites, are also used in the industry, i.e. in the production of some hormonal compounds [10]-[12]. Toxins are mostly found in molds produced by several fungal species but, the most known fungal producers of toxins are; Penicillium sp., Aspergillus sp. and Fusarium sp. [13]. There are a variety of secondary metabolites produced by fungal species, some of these toxins are hazardous to plants, humans and animals, e.g. Aflatoxins, Fumonisins, DON, Ochratoxins, etc. [1], [13], [14]. Some types as elucidated in [15]-[17], i.e. Ochratoxins (A, B and C), Aflatoxins (AFB 1, AFB 2, AFG 1 and AFG 2), Fumonisin (FB1) [9], [16], [18], [19], and were determined to be detrimental to human health. Although, secondary metabolites occurrence in the environment and in agricultural food products as well as feeds, are a serious concern, not only to human health clinical outcomes [20]-[22], there is potential for huge economic losses due to medical health claims and production losses from agricultural product producers [6], [23], [24]. Some secondary metabolites observed in agricultural produce include 11 Ketotestosterone (3) and Silibinin which have some clinical and health advantages [25]-[28]. Previous studies have revealed that $C$. bertolletiae could be cyanide resistant and be able to biodegrade the compound (cyanide) [29] but, there is little or no evidence in literature available on secondary metabolites produced by cyanide resistant Cunninghamela bertholletiae sp.

\section{MATERIAL AND METHODS}

\section{A. Fungal Isolation, Identification and Characterization}

Fungal (Cunninghamella bertholletiae) isolation, identification and characterization was done using a culture-based technique, from cassava-cultivated soil that was sprinkled into a Potato Dextrose Agar (PDA) (Merck, Germany) and incubated for a duration of $168 \mathrm{hrs}$, at room temperature. After several sub-culturing cycles, a pure colony of C. bertholletiae was aseptically transferred into Nutrient Broth medium (Merck, Germany), in a $40 \mathrm{~mL}$ airtight multiport shake flasks. The cyanide concentration (as $\mathrm{KCN}$ ) was set at $100 \mathrm{mg}$ $\mathrm{CN}^{-} / \mathrm{L}$ and the culture was incubated at $37^{\circ} \mathrm{C}$ for $168 \mathrm{hrs}$, followed by spread-plating on PDA and the PDA plates were incubated at room temperature for a further $168 \mathrm{hrs}$. This was done to assess fungal/ organisms resistance and/or tolerance to 
cyanide. A pure fungal strain was isolated from the PDA and re-inoculated in Nutrient Broth for 24hrs for subsequent DNA extraction and sequencing procedures, which were conducted as described elsewhere [29]. The generated nucleotide sequence was analysed using CLC main workbench 7 followed by a BLAST (Basic Local Alignment Search Tool) provided by NCBI (National Centre for Biotechnology Information) and was identified and assigned the accession number: KT275316.

\section{B. Secondary Metabolites Extraction and Identification}

C. bertholletiae was grown on a PDA for a period of $168 \mathrm{hrs}$ and thereafter, the mycelia was removed from the PDA using a surgical blade. A mass $(0.05-0.4 \mathrm{~g})$ of the extracted mycelia was inoculated into a $40 \mathrm{~mL}$ Erlenmeyer flask containing $25 \mathrm{~mL}$ of Nutrient Broth (Merck, Germany), followed by incubation in an orbital shaker at $37{ }^{\circ} \mathrm{C}$ for a period of $168 \mathrm{hrs}$. Extracts (suspension) were filtered using a No 5 Whatman filter paper in order to obtain extracts free of spores and mycelia [30]. The liquid fraction was transferred into centrifuge tubes followed by centrifugation at $5000 \mathrm{rpm}$ for $10 \mathrm{~min}$ using a Megafuge 1.0 (Kendrol Laboratory products, Germany). The supernatant was transferred into clean $20 \mathrm{~mL}$ sampling tubes while the pellets were discarded.

\section{Mycotoxin (Secondary Metabolites) Extraction and Detection}

Toxins (secondary metabolites) extraction was done using a modified liquid-liquid extraction method [31], [32]. $5 \mathrm{~mL}$ of the extracts were transferred into clean tubes containing $5 \mathrm{~mL}$ of $100 \%$ chloroform (Sigma Aldrich, Germany) and the contents were mixed by inversion 3-5 times, followed by centrifugation at $5000 \mathrm{rpm}$ for $10 \mathrm{~min}$ using a Megafuge 1.0 (Kendrol Laboratory products, Germany). The aqueous phase containing chloroform was transferred into clean tubes while the Nutrient Broth phase was discarded [33]. The aqueous phase was evaporated in a sterile environment at room temperature for 24 hrs followed by complete blow-down using nitrogen $\left(\mathrm{N}_{2}\right)$ gas (Afrox, South Africa). Sample contents were reconstituted (by dilution) using $1 \mathrm{~mL}$ of $100 \%$ methanol (Sigma Aldrich). $1 \mathrm{~mL}$ of the reconstituents was transferred into a LC/MS analysis vial using a $1 \mathrm{~mL}$ glass syringe and $0.2 \mu \mathrm{m}$ Whatman syringe filter. The samples were analysed using LC/MS-TOF 6230 with the mobile phase flow rates as described in Table 1.

TABLE I: LC/MS ELUENTS AND ANALYSIS PARAMETERS

\begin{tabular}{lccc}
\hline \hline Gradient & $\mathrm{A}\left(\mathrm{H}_{2} \mathrm{O}\right)$ & $\mathrm{B}(\mathrm{MeOH})$ & Flow $(\mu \mathrm{L} / \mathrm{min})$ \\
\hline 0 & 85 & 15 & 0.4 \\
30 & 0 & 100 & 0.4 \\
33 & 0 & 100 & 0.4 \\
45 & 85 & 15 & 0.4 \\
50 & 85 & 15 & 0.4 \\
\hline \hline
\end{tabular}

A ToF LC/MS used for analysis/identification of mycotoxins had the following operational parameters; MS Interface Ionisation: Electronspray ionisation (ESI), High vacuum pressure of $1.16 \times 10^{-7} \mathrm{~Pa}$ (Torr), Dry gas temperature of $350^{\circ} \mathrm{C}$, Nebulising pressure of 15 psig, Dry gas flow of $8.0 \mathrm{~L} / \mathrm{min}$, A positive, acquisition mode, a ESI capillary voltage of $3500 \mathrm{kv}$, a mass range scan between 112.9855-966.0007, ToF flow rate of $3 \mathrm{~mL} / \mathrm{min}$, samples injection volume of $5 \mu \mathrm{L}$, with a $\mathrm{C} 8$ column symmetry $\left(150 \times 3.9 \mathrm{~mm}, 5 \mu \mathrm{m}\right.$ at the temperature of $\left.30^{\circ} \mathrm{C}\right)$; a Symmetry C8 guard column: $3.9 \times 20 \mathrm{~mm}, 5 \mu \mathrm{m}$ while, a mobile phase constitute of solvent A (Water), solvent B (Methanol) which were of analytical grade. The identification of the toxins/secondary metabolites from $C$. bertholletiae were done according to $\mathrm{m} / \mathrm{z}$ ratio of library toxins and secondary metabolites.

\section{RESULTS}

C. bertholletiae's toxins/secondary metabolites production was assessed via a fermentation technique in nutrient broth medium with the separation process being done using chloroform, which was followed by the total evaporation of the extracts and subsequent reconstitution in absolute methanol. The compounds listed on Table II were identified based on their molecular features and the extracted ion chromatograms (EICs) are presented in Figure 1(A, B).

Additionally, the compound identification is important due to their impacts on humans and animals. Thus, 11-Ketotestosterone in human's health is used a main source of androgen; known as a human's growth and reproduction hormone; as well as in breast cancer treatment [25], [28], [34] while, Silibinin is an antioxidant, antiviral agent which is used for cancer treatment and treatment liver diseases [26], [27], [35].

TABLE II: C. BERTHOLLETIAE'S SECONDARY METABOLITES IDENTIFIED USING LC/MS

\begin{tabular}{lccc}
\hline \hline Compounds & Formula & $\begin{array}{c}\text { Molar mass } \\
(\mathrm{g} / \mathrm{mol})\end{array}$ & $\begin{array}{c}(\mathrm{m} / \mathrm{z}) \text { to charge } \\
\text { ratio }\end{array}$ \\
\hline 11-Ketotestosterone (3) & $\mathrm{C}_{19} \mathrm{H}_{26} \mathrm{O}_{3}$ & 302.42 & 303.19 \\
Silibinin & $\mathrm{C}_{25} \mathrm{H}_{22} \mathrm{O}_{10}$ & 482.44 & 483.12 \\
\hline \hline
\end{tabular}

The detection of the secondary metabolites on LC/MS was adopted from a method developed by [14], [16], [35]-[37], from which the compound produced moderate signal under a positive acquisition mode. Its chromatographic separation during Electron Spraying Ionization (ESI) of both phases (forward and reverse) revealed a clear peak, while, the compound counts (level) were detected (Figure 1A, B).

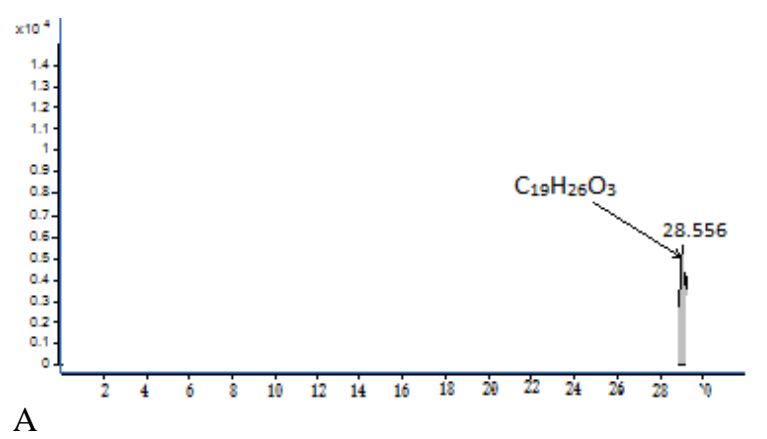




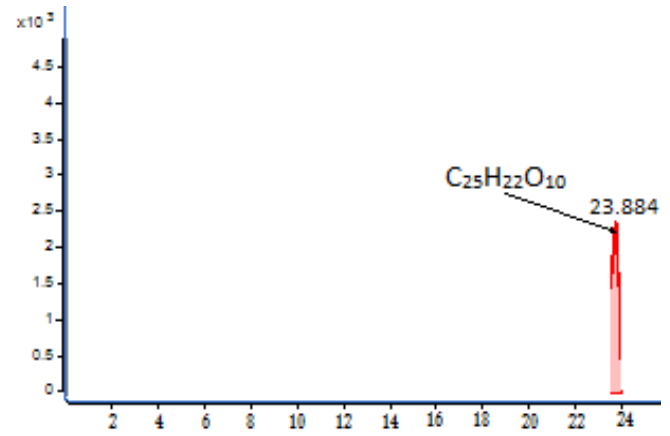

B

Fig. 1. Molecular features and the extracted ion chromatograms (EICs) for secondary metabolites: (A) 11-Ketotestosterone (3), (B) Silibinin

\section{A. 11-Ketotestosterone (3)}

11-Ketotestosterone (3) was detected in a fermentation medium for the cyanide resistant organism. An LC/MS analysis of the sample on a positive mode of acquisition as well as a chromatographic separation through Electron Spraying Ionization (ESI) resulted in a clear peak although its concentration in the sample was low. Thus, the compound counts was $0.5 \times 10^{4} \mathrm{ppm}$ while, its acquisition time was 28.520 $\min$ (Figure 1A).

\section{B. Silibinin}

Similarly, the Silibinin was also extracted from the medium used for fermentation; however, the compound detection through a positive acquisition mode in both the ESI phases resulted in a clear chromatograph peak with a resultant count of approximately $2.5 \times 10^{3} \mathrm{ppm}$ while, the time of acquisition was $23.884 \mathrm{~min}$ (Figure 1B). The observed detection count of Silibinin was higher than that of 11-Ketotestosterone (3).

\section{DISCUSSION}

It is important to observe that secondary metabolites such as; 11-Ketotestosterone are one of human's main source of androgen which is a hormone which facilitates men and females growth and reproduction [25]. Previous studies revealed that androgen receptor activation plays a major role in a treatment of breast cancer [25], [28], [34].

Silibinin is an antioxidant, antiviral, and cell catalyst (pSTAT3) used in the treatment of lung, prostate, breast, gastric and skin cancer, liver disease including the treatment of other malfunctioning humans organs [26], [27], [35], [38].

This study modified the method of [39] for toxins extraction using a fermentation method to obtain fungal $C$. bertholletiae extracts for LC/MS analysis of toxins/secondary metabolites because, the latter appeared easier, faster and cheaper. Thus, the analyses revealed a successful identification of secondary metabolites 11-Ketotestosterone 3 and Silibinin, respectively.

Therefore, it was clear that the acquisition time of the compound (11-Ketotestosterone 3) was high (28.520 min) due to its low concentration in the sample and molecular structure. On the other hand, a high concentration of Silibinin in the sample enabled its rapid detection at a short period of time (23.884 min).
The detected secondary metabolites play a significant role to living organisms, and especially in humans and animals. These compounds may be beneficial and also hazardous to humans in higher concentrations.

\section{CONCLUSION}

This study revealed the production of secondary metabolites from a cyanide resistant and/or tolerant Cunninghamella bertholletiae. Silibinin and 11-Ketotestosterone were successfully produced and identified.

It is, however, recommended that future research should be directed at the evaluation of the secondary metabolite on different $C$. bertholletiae strains and other related fungal organisms.

\section{ACKNOWLEDGEMENTS}

This research is sponsored by the Cape Peninsula University of Technology, through the University Research Fund (URF) Cost code R980.

\section{REFERENCES}

[1] J. I. P. A. A. D. Hocking, 1997. Fungi and Food Spoilage.

[2] T. Zidenga, E. Leyva-Guerrero, H. Moon, D. Siritunga and R. Sayre, 2012. Extending cassava root shelf life via reduction of reactive oxygen species production. Plant Physiology, 159, 1396-1407. https://doi.org/10.1104/pp.112.200345

[3] E. Njumbe Ediage, K. Hell and S. De Saeger, 2014. A Comprehensive study to explore differences in mycotoxin patterns from agro-ecological regions through maize, peanut, and cassava products: A case study, Cameroon. Journal of agricultural and food chemistry, 62, 4789-4797. https://doi.org/10.1021/jf501710u

[4] W. Ellefson, L. Zach and D. Sullivan, 2012. Improving import food safety, John Wiley \& Sons. https://doi.org/10.1002/9781118464298

[5] L. Matumba, M. Sulyok, M. Monjerezi, T. Biswick and R. Krska, 2014. Fungal metabolites diversity in maize and associated human dietary exposures relate to micro-climatic patterns in Malawi. World Mycotoxin Journal, 8, 269-282. https://doi.org/10.3920/WMJ2014.1773

[6] E. Streit, C. Schwab, M. Sulyok, K. Naehrer, R. Krska and G. Schatzmayr, 2013. Multi-mycotoxin screening reveals the occurrence of 139 different secondary metabolites in feed and feed ingredients. Toxins, $5,504-523$. https://doi.org/10.3390/toxins5030504

[7] J. N. Selvaraj, Z. Lu, W. Yan, Y.J. Zhao, F.G. Xing, X.F. Dai and L. Yang, 2015. Mycotoxin detection-Recent trends at global level. Journal of Integrative Agriculture, 14, 2265-2281. https://doi.org/10.1016/S2095-3119(15)61120-0

[8] I. Vanhoutte, K. Audenaert and L. De Gelder, 2016. Biodegradation of mycotoxins: tales from known and unexplored worlds. Frontiers in microbiology, 7, 1-20. https://doi.org/10.3389/fmicb.2016.00561

[9] A. R. Ottesen, B. A. Magnuson, V. Juneja and J. Sofos, 2010. Naturally Occurring Toxins in Plants. Pathogens and Toxins in Foods, 1-512.

[10] A. A. Brakhage, 1999. HAP-like CCAAT-binding complexes in filamentous fungi: implications for biotechnology. Fungal Genetics and Biology, 27, 243-252. https://doi.org/10.1006/fgbi.1999.1136

[11] A. A. Brakhage and V. Schroeckh, 2011. Fungal secondary metabolites strategies to activate silent gene clusters. Fungal Genetics and Biology, $48,15-22$. https://doi.org/10.1016/j.fgb.2010.04.004

[12] A. A. Brakhage, 2013. Regulation of fungal secondary metabolism. Nature Reviews Microbiology, 11, 21-32. https://doi.org/10.1038/nrmicro2916 
[13] A. Marroquin-Cardona, N. Johnson, T. Phillips and A. Hayes, 2014. Mycotoxins in a changing global environment-a review. Food and Chemical Toxicology, 69, 220-230. https://doi.org/10.1016/j.fct.2014.04.025

[14] R. D. Plattner, 1995. Detection of fumonisins produced in Fusarium moniliforme cultures by HPLC with electrospray MS and evaporative light scattering detectors. Natural toxins, 3, 294-298. https://doi.org/10.1002/nt.2620030424

[15] L. Afsah-Hejri, S. Jinap, P. Hajeb, S. Radu and S. Shakibazadeh, 2013. A review on mycotoxins in food and feed: Malaysia case study. Comprehensive Reviews in Food Science and Food Safety, 12, 629-651. https://doi.org/10.1111/1541-4337.12029

[16] G. P. Munkvold and A. E. Desjardins, 1997. Fumonisins in maize: can we reduce their occurrence? Plant disease, 81, 556-565. https://doi.org/10.1094/PDIS.1997.81.6.556

[17] J. H. Williams, T. D. Phillips, P. E. Jolly, J. K. Stiles, C. M. Jolly and D. Aggarwal, 2004. Human aflatoxicosis in developing countries: a review of toxicology, exposure, potential health consequences, and interventions. The American journal of clinical nutrition, 80, 1106-1122. https://doi.org/10.1093/ajen/80.5.1106

[18] M. E. Kimanya, B. DE Meulenaer, B. Tiisekwa, M. Ndomondo-Sigonda, F. Devlieghere, J. Van Camp and P. Kolsteren, 2008. Co-occurrence of fumonisins with aflatoxins in home-stored maize for human consumption in rural villages of Tanzania. Food Additives and Contaminants, 25, 1353-1364. https://doi.org/10.1080/02652030802112601

[19] Srey, C., Kimanya, M. E., Routledge, M. N., Shirima, C. P. \& Gong, Y. Y. 2014. Deoxynivalenol exposure assessment in young children in Tanzania. Molecular nutrition \& food research, 58 (7): 1574-1580. https://doi.org/10.1002/mnfr.201400012

[20] M. Peraica and A.-M. Domijan, 2001. Contamination of food with mycotoxins and human health. Arhiv za higijenu rada i toksikologiju, 52, 23-35.

[21] J. Wagacha and J. Muthomi, 2008. Mycotoxin problem in Africa: current status, implications to food safety and health and possible management strategies. International journal of food microbiology, 124, 1-12. https://doi.org/10.1016/j.ijfoodmicro.2008.01.008

[22] R. Bhat, R. V. Rai and A. A. Karim, 2010. Mycotoxins in food and feed: present status and future concerns. Comprehensive Reviews in Food Science and Food Safety, 9, 57-81 https://doi.org/10.1111/j.1541-4337.2009.00094.x

[23] J. Robens and K. Cardwell, 2003. The costs of mycotoxin management to the USA: management of aflatoxins in the United States. Journal of Toxicology: Toxin Reviews, 22, 139-152. https://doi.org/10.1081/TXR-120024089

[24] J. Wang and X. Liu, 2011. Cost-benefit analysis in setting up limitation standards of aflatoxins in foods. Wei sheng yan jiu= Journal of hygiene research, 40, 150-3, 157

[25] K. A. Usmani, R. L. Rose and E. Hodgson, 2003. Inhibition and activation of the human liver microsomal and human cytochrome P450 3A4 metabolism of testosterone by deployment-related chemicals. Drug Metabolism and Disposition, 31, 384-391. https://doi.org/10.1124/dmd.31.4.384

[26] H. L. Ha, H. J. Shin, M. A. Feitelson and D. Y. Yu, 2010. Oxidative stress and antioxidants in hepatic pathogenesis. World Journal of Gastroenterol, $16,6035-43$ https://doi.org/10.3748/wjg.v16.i48.6035

[27] J. Bosch-Barrera and J. A. Menendez, 2015. Silibinin and STAT3: A natural way of targeting transcription factors for cancer therapy. Cancer Treatment Reviews, 41, 540-546. https://doi.org/10.1016/j.ctrv.2015.04.008

[28] A. Anestis, M.V. Karamouzis, G. Dalagiorgou and A. G. Papavassilliou. 2015. Is androgen receptor targeting an emerging treatment strategy for triple negative breast cancer? Cancer Treatment Reviews, 41, 547-553. https://doi.org/10.1016/j.ctrv.2015.04.009

[29] E. F. Itoba Tombo, A. Waxa, and S. K. O. Ntwampe. 2015. Isolation of an endophytic cyanide resistant fungus Cunninghamella bertholletiae from (Manihot esculenta) and cassava cultivated soil for environmental engineering applications.

[30] K. Manjula, K. Hell, P. Fandohan, A. Abass and R. Bandyopadhyay, 2009. Aflatoxin and fumonisin contamination of cassava products and maize grain from markets in Tanzania and republic of the Congo. Toxin reviews, 28, 63-69. https://doi.org/10.1080/15569540802462214

[31] S. Bankole and O. Mabekoje, 2004. Mycoflora and occurrence of aflatoxin B 1 in dried yam chips from markets in Ogun and Oyo States, Nigeria. Mycopathologia, 157, 111-115. https://doi.org/10.1023/B:MYCO.0000012211.31618.18

[32] V. M. T. Lattanzio, M. Solfrizzo, S. Powers and, A. Visconti, 2007. Simultaneous determination of aflatoxins, ochratoxin A and Fusarium toxins in maize by liquid chromatography/tandem mass spectrometry after multitoxin immunoaffinity cleanup. Rapid Communications in Mass Spectrometry, 21, 3253-3261. https://doi.org/10.1002/rcm.3210

[33] A. A. Ismaiel and J. Papenbrock, 2015. Mycotoxins: producing fungi and mechanisms of phytotoxicity. Agriculture, 5, 492-537. https://doi.org/10.3390/agriculture5030492

[34] E. Pretorius, D. J. Africander, M. Vlok, M. S. Perkins, J. Quanson and K. H. Storbeck, 2016. 11- Ketotestosterone and 11-Ketodihydrotestosterone in Castration Resistant Prostate Cancer: Potent Androgens Which Can No Longer Be Ignored. PLoS ONE 11(7): 0159867. doi:10.1371, 1-17

[35] C. Wing Ying Cheung, N. Gibbons, D. Johnson and D. Nicol, 2009. Silibinin - A Promising New Treatment for Cancer. Anti-cancer agents in medicinal chemistry 10(3):186-95. https://doi.org/10.2174/1871520611009030186

[36] Malone, B. R., Humphrey, C. W., Romer, T. R. \& Richard, J. L. 1998. One-step solid-phase extraction cleanup and fluorometric analysis of deoxynivalenol in grains. Journal of AOAC International, 81(2): 448-452.

[37] B. Warth, A. Petchkongkaew, M. Sulyok and R. Krska, 2014. Utilising an LC-MS/MS-based multi-biomarker approach to assess mycotoxin exposure in the Bangkok metropolitan area and surrounding provinces. Food Additives \& Contaminants: Part A, 31, 2040-2046. https://doi.org/10.1080/19440049.2014.969329

[38] P. Hodek, P. Trefil and M. Stiborova, 2002. Flavonoids-potent and versatile biologically active compounds interacting with cytochromes P450. Chemico-biological interactions, 139, 1-21. https://doi.org/10.1016/S0009-2797(01)00285-X

[39] A. C. Bily, A. J. Burt, A. I. Ramputh, J. Livesey, C. Regnault-Roger, B. R. Philogene and J. T. Arnason, 2004. HPLC-PAD-APCI/MS assay of phenylpropanoids in cereals. Phytochemical Analysis, 15, 9-15 https://doi.org/10.1002/pca.735

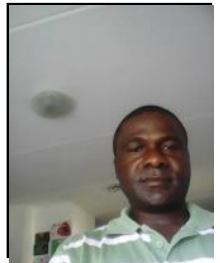

Elie Fereche Itoba-Tombo was born in Makoua (Region de la cuvette) in the Republic of Congo-Brazzaville. He obtained a Diploma of General Studies (DEUG) in Geography in 1994, a Bachelor Degree in Physical Geography in 1996 from the University Marien Ngouabi of Congo - Brazzaville. He obtained an Honours Degree in Natural Sciences (Earth and Environmental Sciences) in 2005 from the University of the Western Cape (UWC)- South Africa, and later completed a Masters of Technology (MTech) degree in Environmental Management in 2010 and in 2018 he obtained a PhD in Environmental Health from the Cape Peninsula University of Technology, Cape Town, South Africa.

He joined CPUT on the 6 March 2007 as a part-time lecturer and is working currently as a lecturer of Environmental Geology, Environmental Management and Ecology in the Department of Environmental and Occupational Studies - District Six Campus.

His research interests are in: 1) soil ecology/biodiversity, 2) microbial extraction/identification and bioprocessing systems (extracellular metabolite production), 3) soil and water pollution and remediation and 4) Environmental management/sustainability

Dr. Elie F. Itoba-Tomb; have published and co-authored several manuscripts listed below:

Peer reviewed book chapters

1. E. F. Itoba Tombo, S.K.O. Ntwampe and J. B. N. Mudumbi, 2017. Leaching of cyanogens and mycotoxins from cultivated Cassava into agricultural soil: effects on groundwater quality, in Aflatoxin, Dr. Lukman Bola Abdulra'uf (Ed.), InTech, ISBN: 978-953-51-5464-8

Peer reviewed: journal articles/conference papers/data journals 
2. L. Mekuto, Y.M. Kim, S.K.O. Ntwampe, M. Mewa-Ngongang, J.N. Mudumbi, N. Dlangamandla, E.F. Itoba-Tombo, E.A. Akinpelu, 2018. Heterotrophic nitrification-aerobic denitrification potential of cyanide and thiocyanate degrading microbial communities under cyanogenic conditions. Environmental Engineering Research. doi.org/10.4491/eer.2018.147

3. John Mudumbi, Seteno Karabo Obed Ntwampe, Lukhanyo Mekuto, Tandi E. Matsha, Elie Fereche Itoba-Tombo. 2018. The role of pollutants in Type 2 Diabetes Mellitus (T2DM) and their prospective impact on phytomedicinal treatment strategies. Environmental Monitoring and Assessment. https://doi.org/10.1007/s10661-018-6634-2

4. Mekuto L., Kim Y. M., Ntwampe S. K. O., Mewa-Ngongang M.,Mudumbi J. B. N., Dlangamandla N., Itoba-Tombo E. F. 2018. Heterotrophic Nitrification-Aerobic Denitrification Potential of Cyanide and Thiocyanate Degrading Microbial Communities under Cyanogenic Conditions. Section: SEWAGE MANAGEMENT AND TREATMENT. 10th Eastern European Young Water Professionals Conference IWA YWP, 7-12 May 2018, Zagreb, Croatia. Pp. 243 - 244. ISBN: 978-953-8168-23-9

5. John Baptist Nzukizi Mudumbi, Seteno Karabo Obed Ntwampe, Lukhanyo Mekuto, Elie Fereche Itoba-Tombo, Tandi E. Matsha, 2017, Are aquaporins (AQPs) the gateway that conduits nutrients, persistent organic pollutants and perfluoroalkyl substances (PFASs) into plants? Springer Science Reviews, 5(1-2), pp. 31-48, DOI: 10.1007/s40362-017-0045-6

6. John Baptist Nzukizi Mudumbi, Seteno Karabo Obed Ntwampe, Tandi Matsha, Lukhanyo Mekuto, Elie Fereche Itoba-Tombo. 2017. Recent developments in polyfluoroalkyl compounds research: A focus on human/environmental health impact, suggested substitutes and removal strategies. Environmental Monitoring and Assessment, 189(8), p.402.

7. Itoba-Tombo, E.F., Obed Ntwampe, S.K., Bell, J.J.A., Nzukizi Mudumbi, J.B. and Mhlangabezi Golela, T., 2017. A decade's (2014-2024) perspective on cassava's (Manihot esculenta crantz) contribution to the global hydrogen cyanide load in the environment. International Journal of Environmental Studies, 74(1), pp.28-41.

8. E. F. Itoba-Tombo, S. K. O. Ntwampe, A. Waxa, A. Paulse, and E. A. Akinpelu. 2016. Screening of fungal (Cunnighamella bertholletiae) pathogenic activity on microbial community in cassava (Manihot esculenta crantz) cultivated soil. Int'l Conf. on Advances in Science, Engineering, Technology \& Natural Resources (ICASETNR-16) Nov. 24-25, 2016 Parys (South Africa). ISBN 978-93-84468-79-8

9. Enoch Akinbiyi Akinpelu, Seteno Karabo Obed Ntwampe, Lukhanyo Mekuto and Elie Fereche Itoba Tombo. 2016. Optimizing the Bioremediation of Free Cyanide containing Wastewater by Fusarium oxysporum grown on Beetroot Waste using Response Surface Methodology. Proceedings of the World Congress on Engineering and Computer Science 2016 Vol II WCECS 2016, October 19-21, 2016, San Francisco, USA. ISBN: 978-988-14048-2-4 ISSN: 2078-0958 (Print); ISSN: 2078-0966 (Online), pg 664 - 670

10. Elie Fereche Itoba Tombo, Anda Waxa, and Seteno Karabo Obed Ntwampe, 2015. Isolation of an Endophytic cyanide resistant fungus Cunninghamella bertholletiae from (Manihot esculenta) and cassava cultivated soil for environmental engineering applications. Accepted peer reviewed conference proceedings of 7th International Conference on Latest Trends in Engineering and Technology (ICLTET'2015), Pretoria (South Africa)

Posters Conference oral presentations/Abstracts

11. E. F. Itoba Tombo, S.K.O. Ntwampe, J.B. Mudumbi. 2014. Cyanogen loading effects on terrestrial ecosystem and groundwater quality in agricultural soil. Abstract No. P1. 034 (conference proceeding p. 123) Abstract and poster presentation at the First Global Soil Biodiversity Conference. 2-5 December 2014.Dijon,France,

https://dspace.uevora.pt/rdpc/bitstream/10174/12805/.../Book\%20of\%20Abst racts.pdf (International conference)

12. Itoba Tombo, E. F., Thomas, A., Stam, A,. 2010: Land-use impacts on water quality of the Bottelary River in Cape Town, Western Cape. Paper (PowerPoint) presentation at

the International conference "Knowledge collaboration and learning for sustainable innovation (ERSCP/EMSU)" co-organised by Delft University of Technology (TUD)-Netherland and the Cape Peninsula University of Technology (CPUT) from 25-29 October 2010. (International conference)

Poster conference presentations

13. Elie F. Itoba Tombo; Thomas A.; Stam. Ed. and Chingombe, W. 2013. Flux of the chemical compounds within the Bottelary River system, Cape Town, RSA. Abstract No. 33A (conference proceeding p. 219) of the 10th
International Conference of Phytotechnologies. October 1-4 2013; Syracuse, New York, USA (International conference) 